\title{
EFFECT OF INTERVENTION IN LATE AND POST TERM PREGNANCIES ON NEONATAL AND EMPLOYED WOMEN OUTCOMES
}

\author{
By
Muftah Abdallah Suwan, Butheina Khalil Gerriw, Omer Seriti, Hajer Amer, and Ahmed Ezzat AbdElaziz* \\ Misurata Medical Center, Gynecology and Obstetrics Department, Faculty of Medicine, \\ University of Misurata, Libya, and Community and Industrial Medicine Department, \\ Faculty of Medicine, Al-Azhar University, Egypt*
}

\begin{abstract}
Background: A prolonged pregnancy is a pregnancy between $41+0$ weeks through $41+6$ weeks of gestation. It is also known as late-term pregnancy measured from the first day of the last menstrual period. It is approximately 5 to 10 percent of all pregnancies. The pregnancy which continued beyond 42 weeks' gestation is called post term or post maturity pregnancy. It is about $1 \%$. Postterm pregnancy is associated with higher risk of maternal and fetal complications such as emergency cesarean delivery, postpartum hemorrhage, birth canal injuries, macrosomia, meconium aspiration syndrome, and admission to neonatal intensive care unit (NICU).
\end{abstract}

Objective: To determine the effects of induction of labor in late and post term pregnancies on mode of deliveries, to determine the risk of obstetrical and fetal complications in prolonged pregnancy in employed women, to compare the maternal and neonatal outcomes between induction of labor group and expectant management group, and to detect prenatal risk indicators of prolonged pregnancy in employed women.

Subjects and Methods: Across sectional descriptive study of selected data included deliveries of late and post term pregnancies at Misurata Medical Center from the 1st of January to 30th of June 2018 where 188 patients were included in the study. Women with gestational age between $41+0$ to $42+6$ completed weeks and beyond were included in the study. A comparison between expectant management and induction of labor management was conducted to evaluate maternal, fetal and neonatal complications.

Results: The rate of cesarean deliveries was a significantly higher for induction of labor (IOL) group (26\%) compared with expectant management group $(9.6 \%)$. Besides, the more frequent occurrence of all types of perineal lacerations and episiotomies (51\% in IOL group vs $16 \%$ in expectant management group) in women with vaginal deliveries.

The total number of deliveries was 2248 , the full term deliveries were $1890(84 \%)$, preterm deliveries were $170(7.6 \%)$, late and post term deliveries were 174 and 14 (7.7\% and $0.8 \%)$ respectively.

Cesarean deliveries in women with prolonged pregnancies 33 patients (17.6\%); $4.8 \%$ were elective LSCS due to previous uterine scar and prolonged pregnancies and $12.8 \%$ were emergency LSCS because of pathological cardio-tocography (CTG), failed IOL and maternal exhaustion.

Postterm case, about $24 \%$ of cases had previous history of prolonged pregnancy, $20 \%$ with family history of prolonged pregnancy. $15 \%$ of cases were primigravida, 51.6\% were between P1-P3, and 33\% were more than P3 .

In present study, neonatal outcome 98.9\% were normal Apgar and 1.06\% were with low Apgar less than 7 at five minutes.

Thirty six neonates (19\%) were admitted to neonatal ICU, for observation and supportive management because of transient tachypnea 1-2 days after operative deliveries and discharge with good state.Regarding 
birth weights of neonates among women in IOL group and who had spontaneous onset labor (84\%)ranging from2500 grams (g) - $4000 \mathrm{~g}$, only(2.7\%) were large infants more than $4000 \mathrm{~g}$.

Conclusion: Induction of labor in late and postterm pregnancies was associated with increasing the rate of cesarean delivery. However, other maternal and fetal parameters were not affected by IOL.

Key words: effect of intervention, neonatal and employed women outcomes

\section{INTRODUCTION}

A prolonged pregnancy is a pregnancy between $41+0$ weeks through $41+6$ weeks of gestation, also known as late-term pregnancy from the first day of the last menstrual period approximately 5 to 10 percent of all pregnancies (Arora, 2017).whereas the pregnancy which continuing beyond 42 weeks' gestation called post term or post maturity pregnancy about $1 \%$ (Vayssiere et al., 2013).

Post term pregnancy is associated with a higher risk of maternal and fetal complications such as emergency cesarean delivery, postpartum hemorrhage, birth canal injuries, macrosomia, and meconium aspiration syndrome and admission to neonatal intensive care unit (NICU) (Daskalakis and Zacharakis, 2014).

The management of pregnancy beyond 40 weeks' gestation relies on an accurate assessment of the gestational age. A Cochrane review found that, compared with selective ultrasonography, routine prenatal ultrasonography before 24 weeks' gestation provides better gestational age assessment and earlier detection of multiple pregnancies and fetal malformations. Early ultrasound dating also resulted in a 70 percent reduction in the number of pregnancies that were considered post-term Therefore, elective labor induction before 42 weeks' gestation has been proposed to reduce rates of adverse fetal and maternal complications (Vayssiere et al., 2013).

The expectant management group had a significantly higher rate of cesarean deliveries than the induction group resulting from fetal distress, but there was no difference between groups in the rate of cesarean deliveries resulting from dystocia or obstructed labour. No difference was found in perinatal mortality rates, although the study was too underpowered to detect this outcome. When no differences were found in neonatal morbidity outcomes. (Thangarajah and Scheufen, 2016).

The present work aimed to determine the effects of induction of labor in late and post term pregnancies on mode of deliveries, to determine the risk of obstetrical and fetal complications in prolonged pregnancy in employed women to compare the maternal and neonatal outcomes between induction of labor group and expectant management group, and to detect prenatal risk indicators of prolonged pregnancy in employed women.

\section{SUBJECTS AND METHODS}

A cross section descriptive study was performed on deliveries of late and postterm gestation $(41+0$ to $42+6$ weeks $)$ in the first 6 months of $2018\left(1^{\text {st }} /\right.$ January until $30^{\text {th }} /$ June). Data were collected from deliveries of selected period in Misurata Medical Center. Outcomes of pregnancies from 41 weeks, the risk 
factors, mode of delivery, maternal, and fetal outcomes were determined.

The primary maternal outcomes in each group were assessed such as parity, number of cesarean deliveries and vaginal spontaneous delivery. The maternal complications were assessed by occurrence of lacerations or episiotomies, postpartum hemorrhage, and blood transfusion.

The neonatal outcomes were assessed by Apgar score at five minutes, birth weight, and admission to neonatal intensive care unit (NICU).

The inclusion criteria for this study subjects were regular cycles with known last menstrual date, singleton live pregnancy, vertex presentation, and gestational age $41+0$ to 42 week's gestation and beyond. As a routine, women with pregnancy beyond dates were managed expectantly if the amount of liquor was adequate clinically as well as sonographically, and were induced if there was oligohydramnios clinically and/or sonographically, or if fetal compromise was detected clinically and/or by nonstress test (NST) or decreasing fetal movements. The agent for elective induction of labor (IOL) was decided after assessing the Bishop score (if less than 6) and the amount of liquor decreased: either by misoprostol tablet 25 microgram every 6 hours in the posterior fornix of the vagina, or by mechanical way by application of balloon catheter for cervical ripening which defined as extra-amniotic normal saline (EANS). The later was applied for patients who have previous one uterine scar or multiparous women, EANS should be applied for women who have intact membranes.

We compared the maternal, neonatal outcome and mode of delivery between IOL group and expectant management group. In the spontaneous labor group, firstly, expectant management of the women with late-term pregnancies and beyond twice a week to assess fetal wellbeing by non-stress test and the amount of amniotic fluid by ultrasound. Women presented in spontaneous onset of labor with bishop score $>6$ had artificial rupture of membrane and oxytocin augmentation.

Some women had elective cesarean delivery because of previous scar and postdated pregnancies were included in this study.

\section{Ethical approval:}

Informed consents were obtained from all participants during their follow up at clinic, and data confidentiality was maintained throughout the study and any resulting publication anonymously.

\section{Statistical analysis:}

Data were computerized using the Statistical pakage for Social Sciences (SPSS version 21) that used for data entry and analysis. Descriptive statistics were used, and all results were presented as frequencies, means \pm standard deviation and percentages. 


\section{RESULTS}

Normal vaginal Deliveries of late and post-term pregnancies were $155(82 \%)$ compared with 1890 cases $(84 \%)$ of fullterm pregnancies were ended by normal vaginal deliveries.

Most of prolonged pregnancies cases presented with spontaneous onset of labour 124 cases $(80 \%)$ and only 31 cases $(20 \%)$ undergone IOL. 26 of the cases $(83.8 \%)$ were induced electively by misopristol tab 25 microgram every 6 hours vaginally, and 5 cases $(16.2 \%)$ were induced by mechanical method by application of transcervical balloon catheter by extra amniotic normal saline (EANS).

The cases were distributed according to their gestational ages as following 1890 full term cases $(40+6$ days $)$ and 174 cases (41-42 weeks) and 14 of cases (above 42 weeks gestation).cesarean deliveries in women with prolonged pregnancies 33 patients (17.5\%); $4.8 \%$ were elective LSCS most of them due to previous uterine scar and prolonged pregnancies and $12.8 \%$ were emergency LSCS because of pathological cardio-togography (CTG), failed IOL and maternal exhaustion (Table 1).

Table (1): Maternal Demographic Characteristics

\begin{tabular}{|c|c|c|}
\hline Maternal Character & Number & $\%$ \\
\hline $\begin{array}{l}\text { Patients age (years): } \\
<19 \\
20-30 \\
31-40 \\
>40\end{array}$ & $\begin{array}{c}8 \\
114 \\
59 \\
7\end{array}$ & $\begin{array}{l}4.25 \% \\
60.6 \% \\
31.4 \% \\
3.7 \%\end{array}$ \\
\hline $\begin{array}{l}\text { Gestational age at delivery (weeks) } \\
41-42 \text { weeks } \\
>42 \text { weeks }\end{array}$ & $\begin{array}{c}174 \\
14\end{array}$ & $\begin{array}{c}92.6 \% \\
7.4 \%\end{array}$ \\
\hline $\begin{array}{l}\text { Parity } \\
\text { Primi parous } \\
\text { P1-P3 } \\
>\text { P3 }\end{array}$ & $\begin{array}{l}29 \\
97 \\
62\end{array}$ & $\begin{array}{l}15.4 \% \\
51.6 \% \\
33 \%\end{array}$ \\
\hline Previous cesarean section (CS) & 34 & $18.1 \%$ \\
\hline Women undergone to second cesarean section (CS) & 16 & $8.5 \%$ \\
\hline Primi parous ended by CS & 12 & $6.4 \%$ \\
\hline $\begin{array}{l}\text { Maternal outcomes: } \\
\text {-All types of lacerations\&episiotomy. } \\
\text { post partum hemorrhage(PPH) } \\
\text { Blood Transfusion }\end{array}$ & $\begin{array}{c}38 \\
5 \\
4\end{array}$ & $\begin{array}{l}20.2 \% \\
2.7 \% \\
2.1 \%\end{array}$ \\
\hline $\begin{array}{l}\text { Mode of delivery: } \\
\text { *Spontaneous labor } \\
\text { *Induction of labor; } \\
\text {-Misoprostol } \\
\text {-EANS } \\
\text { *Operative delivery; } \\
\text {-elective (CS) } \\
\text {-urgent (CS); } \\
\text { Pathological CTG } \\
\text { Maternal cause } \\
\text { Failed IOL }\end{array}$ & $\begin{array}{c}124 \\
31 \\
26 \\
5 \\
33 \\
9 \\
24 \\
8 \\
14 \\
2\end{array}$ & $\begin{array}{c}66 \% \\
16.5 \% \\
- \\
- \\
17.6 \% \\
4.8 \% \\
12.8 \% \\
- \\
- \\
-\end{array}$ \\
\hline $\begin{array}{l}\text { Neonatal outcomes: } \\
\text { *Birth weight; } \\
<2500 \mathrm{~g} \\
2500-4000 \mathrm{~g} \\
>4000 \mathrm{~g} \\
\text { * Apgar score. } \\
\text { * Normal apgar } \\
\text { <7 } \\
\text { *MSAF } \\
\text { *Admission to NICU } \\
\text { *congenital anomalies }\end{array}$ & $\begin{array}{c}5 \\
159 \\
24 \\
\\
186 \\
2 \\
39 \\
36 \\
2\end{array}$ & $\begin{array}{c}2.7 \% \\
84.6 \% \\
12.8 \% \\
\\
98.9 \% \\
1.1 \% \\
20.7 \% \\
19.1 \% \\
-\end{array}$ \\
\hline
\end{tabular}




\section{EFFECT OF INTERVENTION IN LATE AND POST TERM PREGNANCIES...}

Only $2 \%$ of patients had got postpartum hemorrhage. However no

significant difference between IOL and spontaneous labor group (Figure 1).

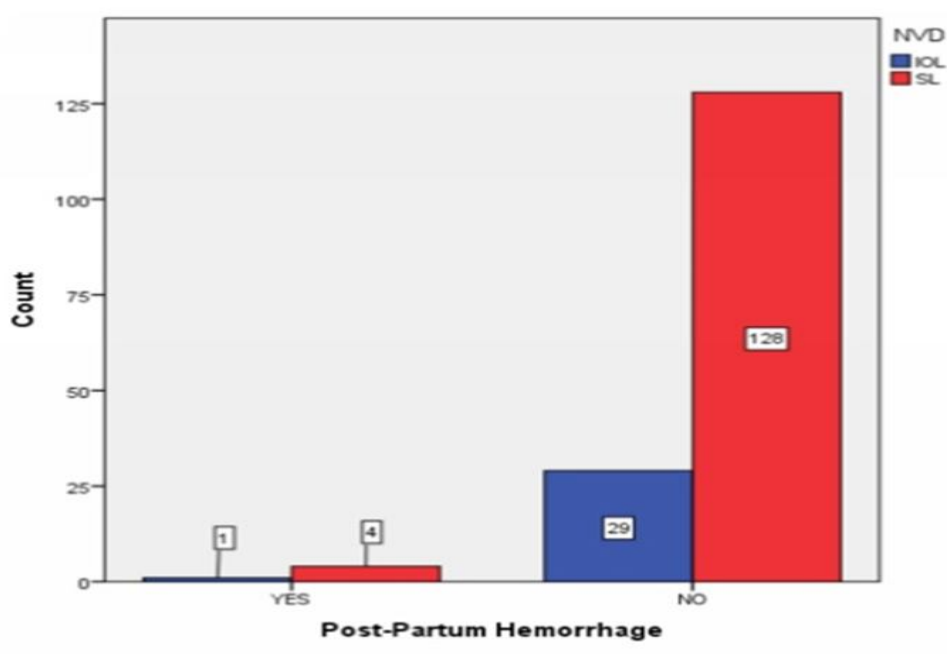

Figure (1): Comparison between IOL group and spontaneous labor group regarding to maternal complications (postpartum hemorrhage)

Normal vaginal Deliveries of late and post-term pregnancies were $155(82.4 \%)$ in relation to only $33(17.6 \%)$ ended Caesarean section. According to gestational ages in the studied group 174 cases $(92.6 \%)$ were between $41-42$ weeks and 14 (7.4\%)of cases were above 42 weeks gestation. According to parity there are 29 cases $(15.4 \%)$ were primigravida, 97 cases $(51.6 \%)$ were between P1-P3, and $62(33 \%)$ were more than P3 (table 2).

Tables (2): Distribution according to of mode of deliveries, gestational age, and parity.

\begin{tabular}{|c|c|c|}
\hline According to mode of deliveries & 188 & $100 \%$ \\
\hline Normal vaginal delivery & 155 & $82.4 \%$ \\
\hline Caesarean section & 33 & $17.6 \%$ \\
\hline According to Gestational age & Number $=188$ & $100 \%$ \\
\hline $41-42$ weeks & 174 & $92.6 \%$ \\
\hline above 42 weeks & 14 & $7.4 \%$ \\
\hline According to gravida & $\mathrm{N}(188)$ & $100 \%$ \\
\hline P0 & 29 & $15.4 \%$ \\
\hline P1-P3 & 97 & $51.6 \%$ \\
\hline More than P3 & 62 & $33 \%$ \\
\hline
\end{tabular}


Risk factors were present in more than half of the cases, including Previous history of prolonged pregnancy and
Family history of prolonged pregnancy (table 3).

\section{Table (3): Risk factors in postterm cases:}

\begin{tabular}{|c|c|c|}
\hline Risk factors & Total No.=188 & $\%$ \\
\hline Previous history of prolonged pregnancy & 45 & $23.9 \%$ \\
\hline Family history of prolonged pregnancy & 38 & $20.2 \%$ \\
\hline
\end{tabular}

According to Apgar score 186 of cases (98.94\%) were normal Apgar and only 2 cases $(1.06 \%)$ were with low Apgar less than 7 at five minutes, however there is no significant difference in neonatal outcomes between induction of labor groups and expectant management group. According meconium staining 149 cases $(79.3 \%)$ were with clear liquor and 39 cases $(20.7 \%)$ were meconium staining fluid ranging to (I, II, III) grades grade $1=$ 25 cases $(13.3 \%)$ and gredes 2 to $3=14$ cases $(7.4 \%)$. According to birth weight only $5(2.6 \%)$ were with birth weight less than $2500 \mathrm{~g}$ but 159 cases $(84.6 \%)$ of birth weight were from 2500 grams $(\mathrm{g})$ to $4000 \mathrm{~g}$, few percentage are large infants 24 cases (1 2.8\%) were more than $4000 \mathrm{~g}$ (there are no difference in birth weights of neonates of late and post-term pregnancies, relatively increasing birth weights gradually with increasing the patients' parity states (table 4).

Table (4): Neonatal outcome according to Apgar score, meconium staining,and birth weight.

\begin{tabular}{|c|c|c|c|c|}
\hline According to Apgar score & Total $=188$ & $\begin{array}{c}\text { Spontaneous } \\
\text { delivery }\end{array}$ & $\begin{array}{c}\text { Induction } \\
\text { of labor }\end{array}$ & $\begin{array}{c}\text { Cesareans } \\
\text { section }\end{array}$ \\
\hline Normal Apgar & $186(98.94 \%)$ & 123 & 30 & 33 \\
\hline Law Apgar (less than 7) & $2(1.06)$ & 1 & - & 1 \\
\hline $\begin{array}{c}\text { According to meconium } \\
\text { staining }\end{array}$ & Total $=188$ & $\begin{array}{c}\text { Spontaneous } \\
\text { delivery }\end{array}$ & $\begin{array}{c}\text { Induction } \\
\text { of labor }\end{array}$ & $\begin{array}{c}\text { Cesarean } \\
\text { section }\end{array}$ \\
\hline Clear liquor & $149(79.3 \%)$ & 103 & 23 & 23 \\
\hline Meconium grade 1 & $25(13.3 \%)$ & 13 & 7 & 5 \\
\hline Meconium grade 2-3 & $14(7.4 \%)$ & 8 & 1 & 5 \\
\hline According to birth weight. & Total $=188$ & $\begin{array}{c}\text { Spontaneous } \\
\text { delivery }\end{array}$ & $\begin{array}{c}\text { Induction } \\
\text { of labor }\end{array}$ & $\begin{array}{c}\text { Cesarean } \\
\text { section }\end{array}$ \\
\hline$<2500 \mathrm{~g}$ & $5(2.6 \%)$ & 3 & 1 & 1 \\
\hline $2500-4000 \mathrm{~g}$ & $159(84.6 \%)$ & 103 & 25 & 31 \\
\hline$>4000 \mathrm{~g}$ & $24(12.8 \%)$ & 17 & 2 & 5 \\
\hline
\end{tabular}

Thirty six neonates (19\%) were admitted to neonatal ICU, for observation and supportive management because of transient tachypnea 1-2 days after operative deliveries and discharge with good state, Aside from no significant difference in neonatal outcomes (Table 5). 


\section{EFFECT OF INTERVENTION IN LATE AND POST TERM PREGNANCIES...}

Table (5): Number of neonatal admission to NICU.

\begin{tabular}{|c|c|c|}
\hline Admission to neonatal ICU & Number $=188$ & $100 \%$ \\
\hline No admission & 152 & $81 \%$ \\
\hline Admission & 36 & $19 \%$ \\
\hline
\end{tabular}

Only two neonates delivered with congenital anomalies, one of them small for gestational age (SGA), cleft lip and palate, the second had congenital heart disease (table 6).

Table (6): Neonatal congenital anomalies.

\begin{tabular}{|c|c|c|}
\hline Congenital anomalies & Number $=188$ & $100 \%$ \\
\hline No congenital anomalies & 186 & $98.9 \%$ \\
\hline Congenital anomalies & 2 & $1.1 \%$ \\
\hline
\end{tabular}

\section{DISCUSSION}

In the present study 5\% women with prolonged pregnancies had elective CS. Of the remaining 124 women $66 \%$ had spontaneous labor and 31 women $16.5 \%$ were induced either because of evidence of oligohydramnios or non-assuring, the primary objective of treatment should be to identify the fetus at risk and thereby to plan an appropriate management. The decision regarding the expectant versus active management of post-term /prolonged pregnancy should depend on balancing the effectiveness of induction against the effectiveness of increased fetal surveillance for preventing fetal and neonatal loss (Stock and Ferguson, 2012).

We have observed that there was lower rate in the presence of meconium staining in the study cases where labour was induced, compared to that women whose had spontaneous labour. It was also observed that elective induction was associated with the increasing in the rate of operative deliveries. Overall there was no significantly increased in perinatal mortality in study cases as compared that with full-term deliveries. If a woman with prolonged pregnancy has adequate amount of liquor and there is no fetal compromise, she could be managed expectantly. However if there is compliance problem or evidence of decreasing liquor or nonassuring fetal condition detected by ultrasonography and, or NST, intervention is imperative (Sepand and Kennrdy, 2018).

Advances in obstetric and neonatal care have lowered the absolute mortality risk. However, retrospective studies of these so-called post-term pregnancies have found an increased risk to the mother and fetus (Olesen et al., 2013).

Some studies that failed to show a reduction in fetal/neonatal morbidity were diluted by poorly dated pregnancies that were not necessarily post-term. In addition, the potential for increasing the risk for cesarean delivery with a failed induction is far less likely in the era of safe and effective cervical ripening agents. About one fifth of induction fails requiring emergency cesarean delivery, although there is strong evidence supporting IOL for management fetal indications (Sepand and Kennrdy, 2018). 
Several studies found that routine labor induction at 41 weeks' gestation resulted in lower perinatal mortality rates but similar cesarean delivery rates. Approximately, 500 women needed to be induced to prevent one perinatal death. The number may be higher over the last two decades and accounts for up to $20 \%$ in United States and United Kingdom, with increased risk of cesarean deliveries particularly in nulliparous (Wood et al., 2014).

The choice of which method used for IOL is controversial. In our study, the comparison between labor induced by misoprostol which applied in posterior fornix of the vagina. The second way is a balloon catheter application into cervical canal. It is cheap, safe method, and it considered effective way which carry risk of a lower uterine hyper stimulation, but its safety are yet to be proven in women with previous cesarean delivery (Church and Katakam, 2010).

The preponderance of the evidence from these studies, including metaanalyses, find that not only is rate of cesarean delivery not increased in women who were randomized to routine induction of labor, but also more cesarean deliveries were performed in the non-induction groups, and the most frequent indication was fetal distress (Arora, 2017).

Routine induction at 41 weeks of gestation does not increase the cesarean delivery rate, and may decrease it without negatively affecting perinatal morbidity or mortality. In fact, both the woman and the neonate get benefit from a policy of routine induction of labor in well-dated, low-risk pregnancies at 41 weeks' gestation (Chai et al., 2018). A policy of routine induction at 40 weeks' has few benefits, and there are multiple reasons not to allow a pregnancy to progress beyond 42 weeks (Arora, 2017).

Elective induction of labor is increasingly being used as a management strategy (Sepand and Kennrdy, 2018). While this management may be reasonable in a practice that allows 48 hours or more for the management of the latent phase and the first stage of labor overall, in a setting where induction of labor is called a failure after 18-24 hours, it will likely further increase the cesarean delivery rate (Caughey and Bishop, 2009).

IOL should be offered for low-risk pregnant women between $41+0$ and $42+0$ weeks to avoid the prolonged pregnancy risks. For women who don't like IOL, increase antenatal monitoring consists of estimation of AFI and CTG according to RCOG (Pundir and Coomarasamy, 2016).

However, elective induction of labor is increasingly being used as a management strategy (Sepand and Kennrdy, 2018). This management may be reasonable in a practice that allows 48 hours or more for the management of the latent phase and the first stage of labor overall, in a setting where induction of labor is called a failure after 18-24 hours. It will likely further increase the cesarean delivery rate (Sepand and Kennrdy, 2018).

\section{CONCLUSION}

Our study suggested that an induction of labor in late and postterm pregnancies is associated with increasing the rate of cesarean delivery. However, other maternal and fetal parameters were not affected by IOL. 


\section{EFFECT OF INTERVENTION IN LATE AND POST TERM PREGNANCIES...}

Management of women with late and postterm pregnancies should be individualized, taking into a consideration the amount of liquor and the findings of sonography and NST. Nevertheless, it has to be kept in mind that with increasing gestational age beyond $41+0$ weeks, the rate of maternal and neonatal complications rise, which indicated that prolonged pregnancy should be delivered promptly.

Overall the decision of whether or not prolonged pregnancies should be induced cannot be conclusively clarified. The opinion should be taking individually by obstetric consultant together with the patients after a full knowledge about advantage and disadvantages.

\section{REFERENCES}

1. Arora $S$ (2017): Self-assessment and review obstetrics. Eur J Obstet Gynecol 9. 10:229.

2. Chai $Y, Q u ~ M$ and Jin $M$ (2018): Application effect of single balloon catheter in labour induction of pregnant women in late-term and their influences on stress and inflammatory responses. Experimental and Therapeutic Medicine, 15: 3352-3356.

3. Caughey AB and Bishop JT (2009): Maternal complications of pregnancy increase beyond 40 weeks of pregnancy increase beyond 40 weeks of gestation in low-risk women. J Perinatol., 26(9):540-5.

4. Church $E$ and Katakam N (2010): Outcomes of different methods of induction of labour. BMJ, 207-211.
5. Daskalakis G and Zacharakis D (2014): Induction of labor versus expectant management for pregnancies beyond 41 weeks. J maternal Fetal Neonatal Med., 27(2): 173-176.

6. Olesen AW, Westergaard JG and Ginery BI (2013): Perinatal and maternal complications related to postterm delivery: a national register-based study, 1978-1993. Am J Obstet Gynecol., 189:222-7.

7. Pundir $J$ and Coomarasamy A (2016): Obstetrics, Evidence- Based Algorithms, 1.Bell and Bain Ltd, UK, 237-238.

8. Sepand A and Kennrdy M (2018): Deriving a clinical prediction tool to measure the success of labor induction [12OP]. Obstet Gynecol 12.,131: 45.

9. Stock S and Ferguson E (2012): outcomes of elective induction of labour compared with expectant management: population based study. BMJ, 344:1-13.

10. Thangarajah $F$ and Scheufen $P$ (2016): Induction of labor in late and postterm pregnancies and its impact on maternal and neonatal outcome. Geburtsh Frauenheilk,76: 793-798.

11. Vayssiere C, Haumante JB, and Chartry A (2013): prolonged and post-term pregnancies: guidelines for clinical practice from the French College of Gynecologist and Obstetricians (CNGOF). Eur $\mathbf{J}$ Obstet Gynecol.,17, 01.026.

12. Wood S, Cooper S, and Ross S (2014): does induction of labour increase the risk of caesarean section? A systematic review and meta- analysis of trials in women with intact membranes. BJOG, 121: 674-685. 


\section{تأثير التحفيز الصناعي للولادة في النساء ذوات الحمل الملديل وتتائجه على الأم العاملة والولئيد

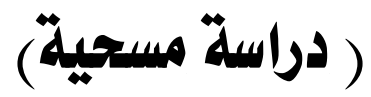

مفتاح صوان - بثينة خليل قريو - عمر السريتي ـ هاجر عامر - أحم عزت عبدالعزيز* تعرئ)

مركز مصراتة الطبى ـ جامعة مصراته ـ كلية الطب ـ قسم النساء والتوليد ليبيا و جامعة الازهر - كلية الطب ـ

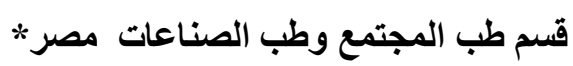

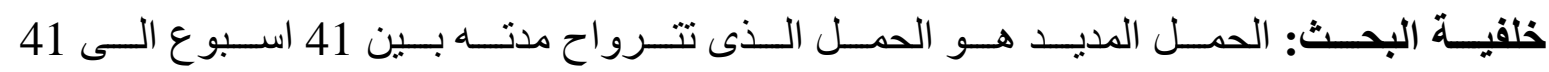

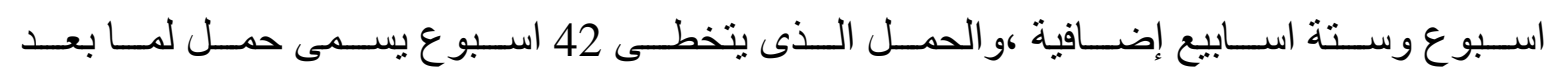

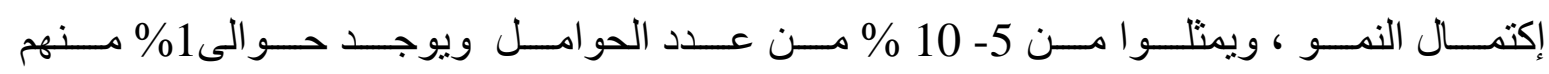

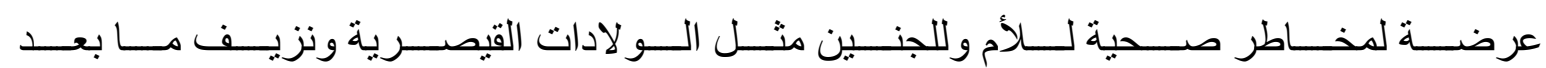

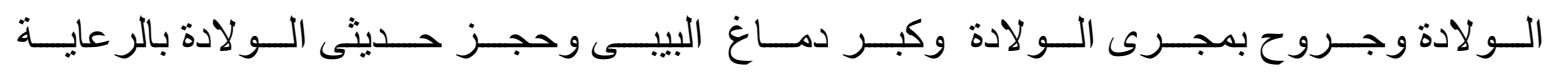

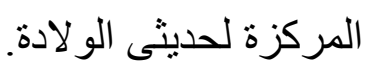

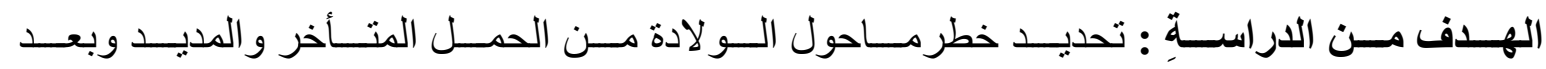

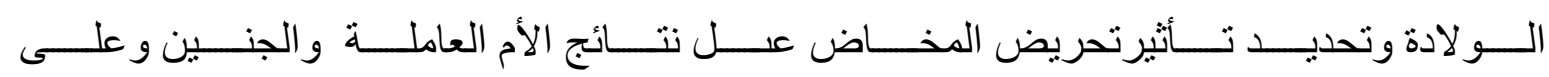

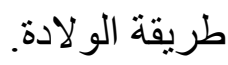

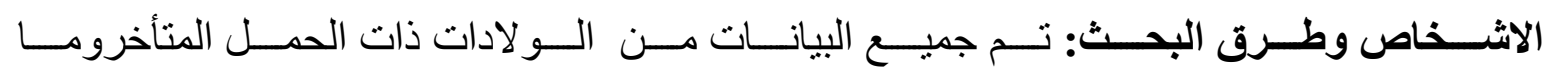

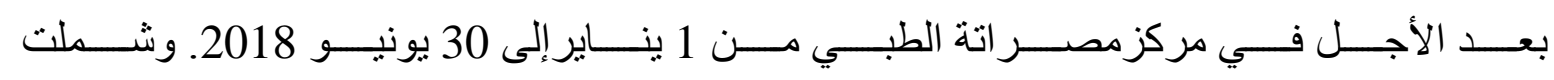

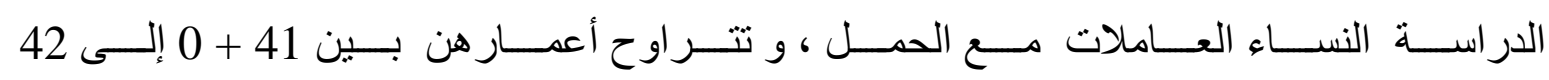

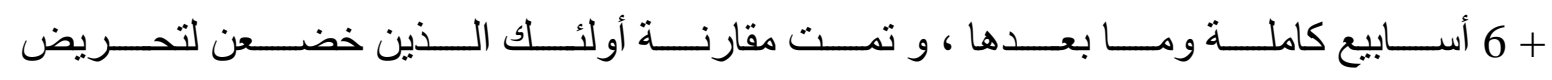

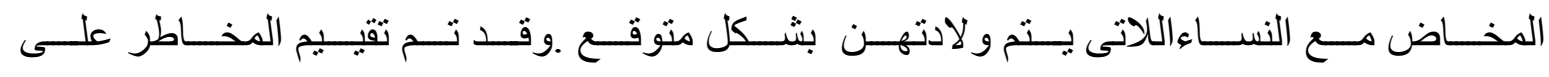
الأم والطفل .وتم تصنيف هؤلاء النساء إلى مجمو عتين:

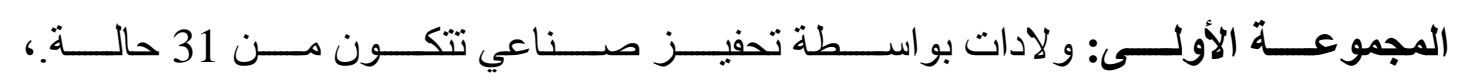

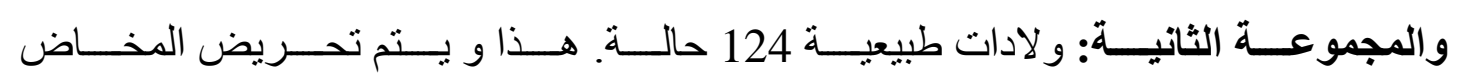

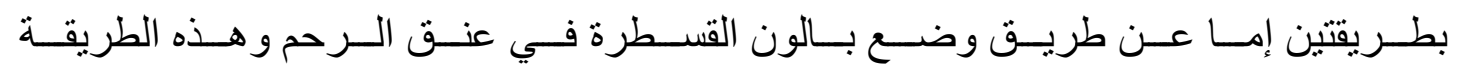




\section{EFFECT OF INTERVENTION IN LATE AND POST TERM PREGNANCIES...}

تســتعمل لنســاء اللــواتي لــديها أكثتـر مــن ثــلاث و لادات او لــديهاو ولادة قيصــرية. ،

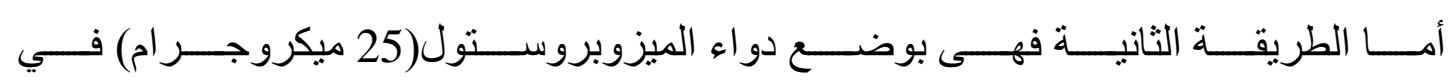
مهبل المريضة ، ويمكن تكرار الجر عة كل 6 ساعات.

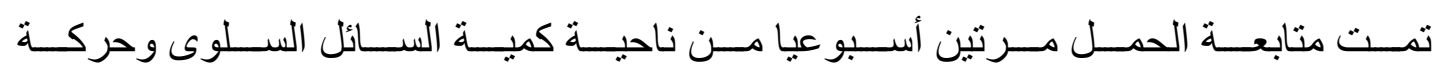

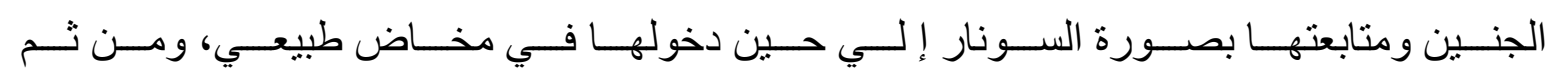

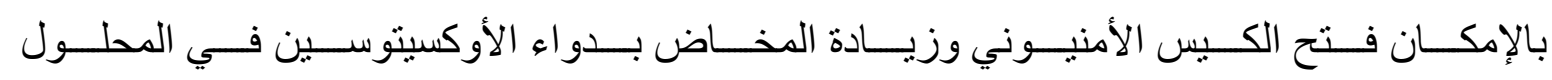
السكري عن طريق الوريد.

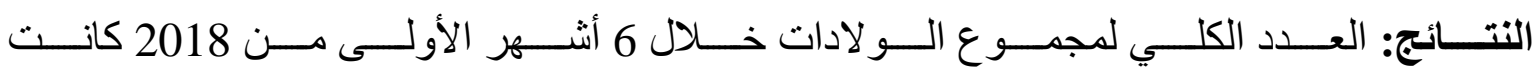

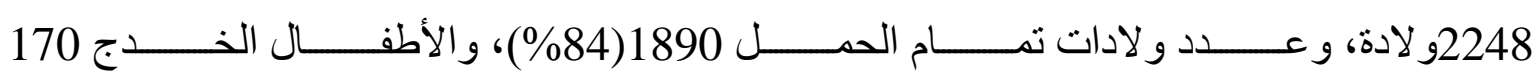

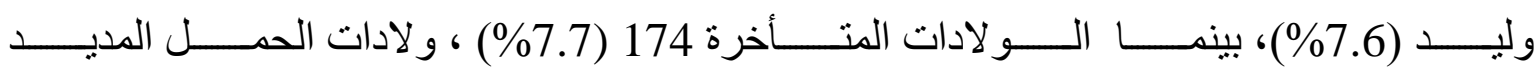
كانت 14 ( \%

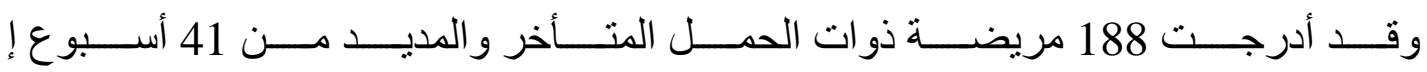

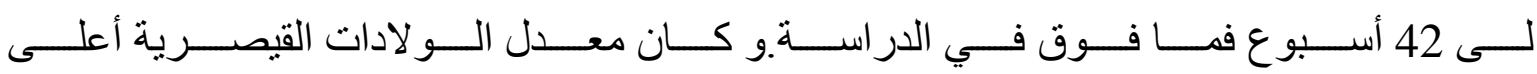

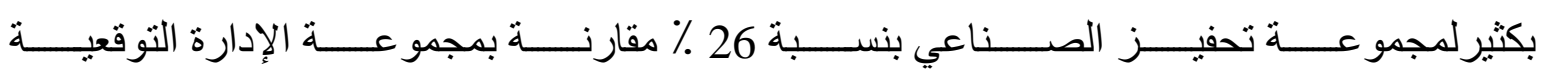

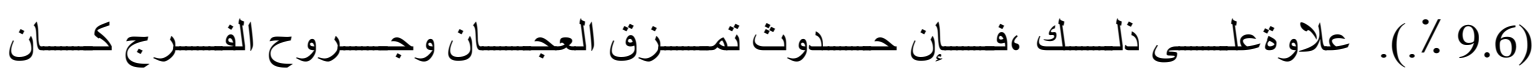

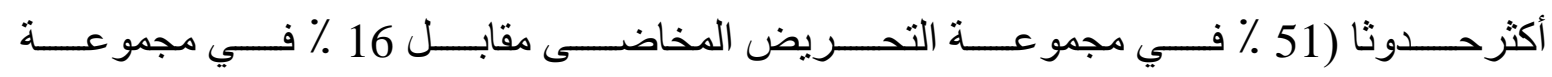

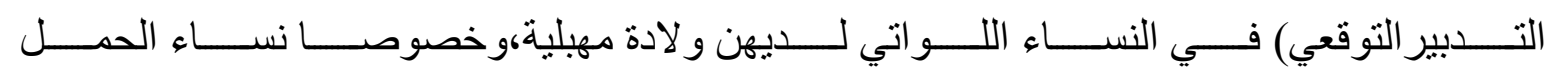
الأول.

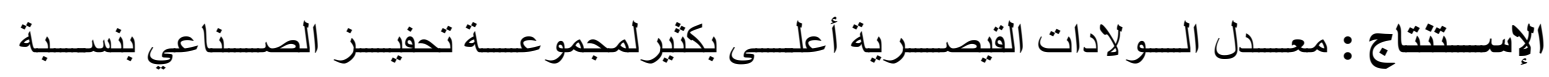
26 \% مقارنة بمجمو عة الإدارة التوقعية (9.6 \%). 